\title{
CHEN WEI 陳偉 (ED.), QIN JIANDU HEJI 秦簡牘合集 [CORPUS OF QIN DOCUMENTS WRITTEN ON BAMBOO AND WOOD]: A REVIEW ARTICLE
}

\section{Olivier Venture*}

Chen Wei 陳偉 (ed.), Qin jiandu heji 秦簡牘合集 [Corpus of Qin documents written on bamboo and wood]. Wuhan: Wuhan daxue, 2014, 7 vols.

\begin{abstract}
The Qin jiandu heji 秦簡牘合集 [Corpus of Qin documents written on bamboo and wood] is the result of a long-term teamwork and collaboration project, directed by Professor Chen Wei 陳偉 of Wuhan University. This publication provides a new, updated edition of seven collections of Qin documents, including those from Shuihudi 睡虎地 (Tomb 4 and 11), Longgang 龍崗 (Tomb 6), Haojiaping 郝家 坪 (Tomb 50), Zhoujiatai 周家臺 (Tomb 30), Yueshan 获山 (Tomb 36), and Fangmatan 放馬灘 (Tomb 1). Although former editions have not become entirely useless for the various reasons evoked in this article, Qin jiandu heji should now be considered the new standard edition for any serious academic research on those materials.
\end{abstract}

The seven large-format volumes of the Qin jiandu heji propose a new and updated edition of the most important Qin manuscripts excavated during the twentieth century. Consummating recent trends in Chinese scholarship, this work can be considered beyond a doubt the new standard edition for all texts concerned.

The Qin jiandu heji is the result of the long-term collective research project "Global Edition and Research of Qin Documents on Bamboo and Wood" (Qin jiandu de zonghe zhengli yu yanjiu 秦簡牘的綜合整 理與研究, \#08JZDoo36) directed by Chen Wei 陳偉, professor of the School of History and director of the Center for the Study of Bamboo and Silk Manuscripts at Wuhan University (Wuhan daxue Jianbo yanjiu zhongxin 武漢大學簡帛研究中心). Initiated in 2008, the project was financially supported by the Ministry of Education of the People's Republic of China as a "Key project of Philosophy and Social

* Olivier Venture (Feng Yicheng 風儀誠), École pratique des hautes études (Paris). Olivier.Venture@ephe.sorbonne.fr.

(C) The Society for the Study of Early China and Cambridge University Press 2016 
Sciences Research from the Ministry of Education" (Jiaoyu bu zhexue shehui kexue yanjiu zhongda keti gongguan xiangmu 教育部哲學社會 科學研究重大課題攻關項目). Twenty-six scholars from different institutions were engaged in this project. The main objective was to publish a new edition of all Qin bamboo and wood documents with high-quality images and revised transcriptions and commentaries. Their research also benefitted from numerous recent studies on related Qin documents. A revised and annotated transcription of the first volume of the original edition of the Liye 里耶 bamboo and wooden documents, published in 2012, was one of the publications connected with this project. ${ }^{1}$

On the Qin jiandu heji publication project, the Center for the Study of Bamboo and Silk Manuscripts collaborated with the Hubei Museum (Hubei sheng bowuguan 湖北省博物館), the Hubei Provincial Institute of Cultural Relics and Archaeology (Hubei sheng wenwu kaogu yanjiusuo 湖北省文物考古研究所), the Jingzhou Museum (Jingzhou bowuguan 荊州博物館), the Sichuan Province Museum of Archaeology and Cultural Relics (Sichuan sheng wenwu kaogu bowuyuan 四川省文物 考古博物院), and the Gansu Province Museum of Documents Written on Wood and Bamboo (Gansu jiandu bowuguan 甘肅簡牘博物館).

In his preface, Chen Wei explains that, if appropriate conditions can be met, they will be publishing a second set of volumes gathering Qin texts not included in the Qian jiandu heji, such as the Liye, Wangjiatai 王家臺 Tomb 15, and Yuelu 岳麓 Academy materials. The present publication covers the corpora from seven tombs: Tomb 4 and 11 from Shuihudi 睡虎地 (excavated in 1975), Tomb 6 from Longgang 龍崗 (1989), Tomb 50 from Haojiaping 郝家坪 (1980), Tomb 30 from Zhoujiatai 周家臺 (1993), Tomb 36 from Yueshan 獄山 (1986), and Tomb 1 from Fangmatan 放馬灘 (1986). The Qin jiandu heiji corpus includes thirty-two documents (eight of which are maps), the shortest being a single wood tablet, and the longest a bookmat of more than three hundred bamboo slips. These texts are particularly important for the study of law and divination in Early China, but the corpus also contains letters, calendars, and maps. As there is already a considerable body of scholarship around these materials, I shall focus here not on content but the contribution that this new edition represents to the field of Early Chinese studies.

The importance of the Qin jiandu heji is threefold: it offers better photographs, it improves the modern transcription of the texts, and it provides scholars with a body of footnotes that are detailed and up to date. The pictures published in the corpus are, with a few exceptions,

1. Chen Wei 陳偉 (ed.), Liye Qin jiandu jiaoshi (diyi juan) 里耶秦簡牘校釋（第一卷） (Wuhan: Wuhan daxue, 2012), $496 \mathrm{pp}$. 
black-and-white photographic reproductions. Not all images have the same origin: some have already been published in different books and journals, some are old pictures that had yet to be published, and others are new pictures taken especially for the project (where the materials are sufficiently well-preserved). This last category includes highresolution and infrared images (identified in this edition by a short, wavy line under the slip number). The reader is presented with two sets of pictures for each document: one preserving the original size of the bamboo slips and wooden tablets, and the other enlarged to two times the original. The photographs are sufficiently clear that most of these documents can in fact be read at their actual size (as was the case during the Qin period), the enlargements providing a more comfortable reading experience for those written in very small characters or affected by poor conservation conditions.

Relying on new and unpublished photographs, the editors were able to identify new graphs and propose a more accurate transcription of others that were unclear as previously published. The editors indicate that they were also able to correct a number of Qin graphs misidentified in former editions, thanks to recent developments within paleography. According to the preface of the Qin jiandu heji, the revisions to earlier transcriptions amount to several hundred graphs. That may seem like a lot, but considering that the corpus from Shuihudi Tomb 11 alone contains more than $37,400,{ }^{2}$ the importance of the revised transcriptions must be put into perspective: they may prove crucial for specialists concerned with the exact meaning of a particular sentence, but probably not for readers interested in a more global understanding of these documents.

The apparatus is where the Qin jiandu heji makes another important contribution. The notes include citations from former editions of the manuscripts as well as references-considered by the editors as particularly significant-to specialized articles or books published thereafter. A bibliography of relevant works (almost entirely in Chinese) is added after the annotated transcription of each set of manuscripts. The editors sometimes also include their own interpretation (introduced by the formula jin an 今按) of a particular line to supplement or to correct their predecessors. Finally, specific attention was paid to restore the documents' original form in the rejoining of fragments and the reordering of slips.

So as to complete this general presentation, I would like to discuss specific aspects relating to each set of documents within this corpus.

2. See Wei Desheng 魏德勝, Shuihudi Qin mu jiandu yufa yanjiu 《睡虎地秦墓竹 簡》語法研究 (Beijing: Shoudu shifan daxue 首都師範大學, 2000), 6. 
The Shuihudi documents occupy the first three volumes of the Qin jiandu heji. The first full edition of the manuscripts from Shuihudi Tomb 11 was published in 1990. The 1990 edition includes black-andwhite photographs, transcriptions, and notes for each text as well as a translation in modern Chinese of all texts excepting the two Rishu 日書 (Daybooks), the Biannianji 編年記 (Chronicle), and the first part of the Weili zhi dao 為吏之道 (The Way of Being an Official). ${ }^{3}$ One notes that the transcriptions, notes, and translations are in fact reproduced with minor modification from an earlier book, published in 1978 (except for the two Rishu manuscripts absent from this former publication). ${ }^{4}$ Thus, it might be said that the Qin jiandu heji represents the first complete edition of the Shuihudi documents since the 1990 edition, which was based mainly on an edition completed in 1977.5 For the images, Chen Wei's team found in the Hubei Museum an unpublished set of photographs, different from that published in 1990. This set was clearer, and some slips look better preserved than in the 1990 publication, but at the same time some slips look to have not yet been cleaned-all of which indicates that this set of photographs had been taken earlier on. In the Qin jiandu heji, the editors generally choose, for each slip, the clearer of the two. Nothing in the plates indicates from which set a given slip-picture originates. In a few cases, where the editors feel that both photos provide valuable information, they have decided to publish both pictures, for example slip 20 from the Yeshu 葉書 manuscript (formerly Biannianji). It must be stressed, of course, that though these pictures were unpublished and forgotten for many years, it does not mean that they were unknown to the original editors. The 1978 edition, for example, gives the complete transcription of the text written on the second register of slip 23 of the Yeshu manuscript which, while still readable in the original, is partially effaced in the pictures published in 1990. The Qin jiandu heji also offers infrared photos for slips where the editors deemed them helpful. The result is not always spectacular, but it provides priceless help in deciphering formerly illegible graphs in several cases.

3. Shuihudi Qin mu zhujian zhengli xiaozu 睡虎地秦墓竹簡整理小組 (ed.), Shuihudi Qin mu zhujian 睡虎地秦墓竹簡 (Beijing: Wenwu, 1990), 255 pp.

4. Shuihudi Qin mu zhujian zhengli xiaozu 睡虎地秦墓竹簡整理小組 (ed.), Shuihudi Qin mu zhujian 睡虎地秦墓竹簡 (Beijing: Wenwu, 1978), 321 pp. About this work and former editions, see A. F. P. Hulsewé's introduction to his English translation of the Shuihudi legal texts: Remnants of Ch'in Law: An Annotated Translation of the Ch'in Legal and Administrative Rules of the 3rd century B.C. Discovered in Yün-meng Prefecture, Hu-pei Province, in 1975. Sinica Leidensia 17 (Leiden: E.J. Brill, 1985).

5. Note that the 1990 edition was reprinted by Wenwu 文物出版社 in 2001, but the pictures are not as clear as in the original edition. 
In the process of preparing the current edition, the editors took full advantage of later discoveries, publications, and studies. The publication of the Western Han legal documents from Zhangjiashan 張家山 Tomb 247 shed new light on the Shuihudi materials, and the same can be said of the Rishu manuscripts with the discovery of similar manuscripts in Zhoujiatai Tomb 30 and Fangmatan Tomb 1. At a glance, the difference between this and the 1990 edition, as concerns the legal texts, lies more in the apparatus than the transcription, the apparatus reflecting the clear progress that has been made toward understanding Qin vocabulary, legal and administrative institutions, and practices. A comparison of translations would have given an even clearer indication of the evolution of the editors' understanding of the text, but the Qin jiandu heji, unfortunately, opted out of modern Chinese translations in accordance with current standards in China about the publication of excavated documents.

The three Shuihudi volumes devote a few pages to the two letters written on wooden tablets from Shuihudi Tomb 4. The editors provide black-and-white and infrared photos for both tablets, and color pictures for one. Some graphs previously considered illegible have now been deciphered on the basis of these images.

The fourth volume covers documents from Longgang Tomb 6 and Haojiaping Tomb 50, both corpora mainly concerning Qin law. This is the fourth time that photographs of the Longgang texts have been published, and it is clearly the Qin jiandu heji that provides the best-quality reproductions. Prior to the Qin jiandu heji, the best photographic reproductions were those found in Yunmeng Longgang Qinjian 雲夢龍崗秦簡, published in 1997.6 The latter also contains a hand copy of the manuscripts, but one that is not particularly reliable. A better hand copy and a more accurate transcription can be found in Longgang Qin jian 龍崗秦簡, published in 2001.7 But now, considering the pictures, the transcription, the apparatus, and the rejoining of several slip-fragments, the Qin jiandu heji should replace these two books as the new standard edition. Some scholars might still turn to the 2001 edition, however, out of interest for a good handwritten copy and modern translation absent from the Qin jiandu heji. The Haojiaping wooden tablets, dated to c. 307

6. Liu Xinfang 劉信芳 and Liang Zhu 梁柱 (ed.), Yunmeng Longgang Qinjian 雲夢龍 崗秦簡 (Beijing: Kexue, 1997), 113 pp.

7. Zhongguo wenwu yanjiusuo 中國文物研究所 and Hubeisheng wenwu kaogu yanjiusuo 湖北文物省考古研究所, Longgang Qin jian 龍崗秦簡 (Beijing: Zhonghua 中 華書局, 2001), 179 pp. Whatever the quality of its photographic reproductions, this publication, as indicated in the Qin jiandu heji, benefitted from the use of infrared technology in the decipherment of these documents. 
B.C.E., are the earliest excavated Qin documents written by brush on perishable material. The original archaeological report provides only low-quality photographic reproductions and a transcription. ${ }^{8}$ Betterquality photographs and handwritten copies were subsequently published in various academic journals. ${ }^{9}$ The Qin jiandu heji offers high-quality color photos and infrared pictures of the first tablet. For the second tablet, where the writing was long considered illegible, the editors provide only the infrared, by which they were able to decipher more than fifty previously illegible graphs. The content of the second document is unclear, but it concerns the use of roads or paths in fields, probably in relation to the legal text concerning fields copied on the first tablet.

The fifth volume focuses on the documents from Zhoujiatai Tomb 30. Discovered in 1993 and published in 2001, the documents are divided by contents into three groups: a Rishu-type manuscript, three calendars, and a magical miscellany. ${ }^{10}$ Given their state of preservation, the editors have decided to reuse the photographs from the 2001 edition, adding infrared images for only a few slips. Due probably to a higher printing quality, the pictures are however much clearer in the Qin jiandu heji edition. The transcription is quite close to that published in the 2001 edition as well, the major difference being the reordering of sections of the Rishu; the apparatus, however, is significantly more up to date. Following the Zhoujiatai documents, the fifth volume also contains documents from Yueshan Tomb 36, consisting of two wooden tablets written on both sides. A complete transcription of those documents, without apparatus, was first published in Kaogu xuebao 考古學報 in 2000 as a part of the archaeological report. The report also included photographs of the recto of both tablets. The Qin jiandu heji edition, by contrast, includes a richly annotated transcription and infrared photographs of both the recto and verso of each tablet. Using these infrared

8. Not satisfied with the first preliminary archaeological report, Sichuanese archaeologists recently published a new preliminary report for Haojiaping Tomb 50, which is quite exceptional by Chinese academic standards. See Sichuan sheng wenwu kaogu yanjiuyuan 四川省文物研究院 and Qingchuan wenwu guanlisuo 青川文物管理所, “Sichuan Qingchuan Haojiaping Zhanguo muqun M5o fajue jianbao" 四川青川郝家 坪戰國墓群 M50 發掘簡報, Sichuan wenwu 四川文物 2014.3, 13-19.

9. For a study including hand copies, transcription, and commentary, see, for example, Xu Zhongshu 徐中舒 and Wu Shiqian 伍仕謙, “Qingchuan mudu jianlun” 青川木牘簡論, Guwenzi yanjiu 古文字研究 1992.19, 282-89. For color pictures, see Chutu wenxian yanjiu 出土文獻研究 2007.8, plates 1 and 2 .

10. Hubei sheng Jingzhou shi Zhouliang Yuqiao yizhi bowuguan 湖北省荊州市周 梁玉橋遺址博物館 (ed.), Guanju Qin Han mu jiandu 關沮秦漢墓簡牘 (Beijing: Zhonghua 中華書局, 2001), $261 \mathrm{pp}$. 
photographs, the editors were able to correct several mistakes in the original transcription and decipher graphs once thought illegible. ${ }^{11}$

The last volume, finally, is dedicated to the documents excavated from Fangmatan 放馬灘 Tomb 1, which include two Rishu-type manuscripts, a ghost story, and several local maps. Discovered in 1986, the first complete edition of these materials was published as late as 2009. ${ }^{12}$ The 2009 edition suffers from numerous shortcomings, for example the low quality of the pictures for the map tablets and the absence of notes usually associated with such transcriptions. That said, the photos of the bamboo slips are clear, and the transcription is generally reliable. The layout of the transcription reproduces that of the manuscript, the content of each slip occupying an entire column, and it even reproduces some of the complex diagrammatic layouts so important in Rishu literature. The editors of the 2009 edition, moreover, pay special attention to the various punctuation or reader's marks present in the text, which used not to be the case in such publications. A revised and expanded version of the original archaeological report (initially published in Wenwu in 1989) is also found at the end of this edition. Inside this report, the editors give a short presentation of the main contents of each section of the Rishu material, which is very convenient for the non-specialist. In 2013, a new edition of these materials was published by Sun Zhanyu 孫占宇 with a revised transcription and abundant philological notes, but the maps were excluded. ${ }^{13}$ Most of the photographs in the 2013 edition consist of new infrared pictures, with only a few taken from the 2009 edition. One also notes significant changes in slips order and the rejoining of fragments. Curiously, the 2013 edition is not evoked in the Qin jiandu heji. The standard pictures used in this latest edition are the same as those published in 2009, but the result is clearer due, perhaps, to the quality of the printing. The addition of infrared photos here is furthermore quite nearly systematic. The difference is particularly evident as concerns the maps, for which only infrared images are proposed. Thanks to these new photographs, which are even better than those in the 2013 edition, the editors were able to correct a number of important misreadings. One of the maps,

11. Pictures and transcriptions were first published in Liu Guosheng 劉國勝, “Jiangling Yueshan Qin du 'rishu' yanjiu” 江陵岳山秦牘日書研究, Daiyonkai Nitch $\bar{u}$ gakusha Chūgoku kodaishi rontan ronbunshū: Chügoku shinshutsu shiryōgaku no tenkai 第 四回日中學者中國古代史論壇論文集中國新出資料學の展開 (Tokyo: Kyūko shoin, 2013), 110-20.

12. Gansu sheng wenwu kaogu yanjiusuo 甘肅省文物考古研究所 (ed.), Tianshui Fangmatan Qin jian 天水放馬灘秦簡 (Beijing: Zhonghua 中華書局, 2009), 163 pp.

13. Sun Zhanyu 孫占宇, Tianshui Fangmatan Qin jian jishi 天水放馬灘秦簡集釋 (Lanzhou: Gansu wenhua 甘肅文化, 2013), 296 pp. 
for example, features a graph long read as shang 上 "up" and understood as an indication for the orientation of the map. Following this interpretation, this document has been cited as an example of northup orientation in Chinese maps. The infrared, however, reveals that the inscription in fact consists of two characters reading beifang 北方 "north," the character 方 being misread (upside down) as 上. According to this new reading, the map is said to corroborate the traditional south-up orientation typical of early Chinese maps. The Qin jiandu heji likewise offers considerable revisions and updates to the transcription and apparatus. Unlike in previous editions, however, the Qin jiandu heji editors adopt a horizontal disposition of the text, as per the other volumes, which while perhaps more accessible for modern readers, also strips the text of its original layout.

In summary, the Qin Jiandu heji must now be considered as the new standard edition for all texts concerned. Specialists who work on those documents will find here the best photographs, the most accurate transcriptions, and the most up-to-date philological commentary. Nonspecialists will find a reliable edition based on the highest of academic standards. The editors have adopted a format aimed at providing the best-quality photographic reproductions available for each text, the result of which is a publication more suited for purchase by libraries and research institutions than the individual scholar (the seven volumes weigh more than $20 \mathrm{~kg}$, of which the first volume alone accounts for $5.6 \mathrm{~kg}$ ). One can hope that the editors will follow this in the future with an abbreviated edition, in a smaller, single volume with only the text, which might also include translations into modern Chinese. Either way, there is no doubt that the Qin jiandu heji represents an important achievement in Qin manuscript studies, and that it will contribute greatly to the promotion of new research on Qin-Han culture and society. ${ }^{14}$

14. Note that this corpus can be used in conjunction with the index Qin jian zhuzi suoyin 秦簡逐字索引, which covers the self-same group of texts. See Zhang Xiancheng 張顯成 (ed.), Qin jian zhuzi suoyin (Chengdu: Sichuan daxue, 2010), 487 pp. 


\title{
“陳偉主編《秦簡牘合集》簡介”
}

\author{
風儀誠
}

提要

《秦簡牘合集》是一項由武漢大學陳偉教授主持的長期團隊合作項目 的研究成果。該書提供了以下资料的新釋文及更加清晰的圖片: 睡虎地 $4 、 11$ 號墓簡牘、龍崗 6 號墓簡牘、郝家坪 50 號墓木牘、周家臺 30 號墓簡牘、獄山 36 號墓木牘、放馬灘 1 號墓簡牘。儘管之前相關整 理性著作尚有一定的學術價值, 但毫無疑問《秦簡牘合集》現在成為以 上七批資料的最新必備參考著作, 同時也代表了目前秦簡牘學的最高研 究水平。

Keywords: Qin, excavated texts, bamboo slips, wooden tablets, law, divination

秦代、秦簡牘、出土文獻、法律、日書 